\title{
eNeuro
}

Research Article: New Research / Development

\section{The Conditioning Lesion Response in Dorsal Root Ganglion Neurons Is Inhibited in Oncomodulin Knock-Out Mice}

https://doi.org/10.1523/ENEURO.0477-21.2022

Cite as: eNeuro 2022; 10.1523/ENEURO.0477-21.2022

Received: 11 November 2021

Revised: 20 January 2022

Accepted: 30 January 2022

This Early Release article has been peer-reviewed and accepted, but has not been through the composition and copyediting processes. The final version may differ slightly in style or formatting and will contain links to any extended data.

Alerts: Sign up at www.eneuro.org/alerts to receive customized email alerts when the fully formatted version of this article is published. 4.0 International license, which permits unrestricted use, distribution and reproduction in any medium provided that the original work is properly attributed. 
1. Title: The conditioning lesion response in dorsal root ganglion neurons is inhibited in oncomodulin knockout mice

2. Abbreviated Title: Oncomodulin and the conditioning lesion effect 3. Author names: Jon P. Niemi ${ }^{\mathrm{a}^{*}}$, Talia DeFrancesco-Oranburg ${ }^{\mathrm{a},{ }^{\star}}$, Andrew Cox ${ }^{\mathrm{b}}$, Jane A. Lindborg ${ }^{\mathrm{a}}$, Franklin D. Echevarria ${ }^{\mathrm{a}}$, Jemima McCluskey ${ }^{\mathrm{b}}$, Dwayne D. Simmons ${ }^{\mathrm{b}}$, and Richard E. Zigmond ${ }^{\mathrm{a}}$ ${ }^{a}$ Department of Neurosciences, Case Western Reserve University, Cleveland OH 44106-4975 ${ }^{\mathrm{b}}$ Department of Biology, Baylor University, Waco TX 76798

* Authors contributed equally to this study.

\section{Author contributions}

J.P.N., T.D-O., JAL, F.D.E., D.D.S., and R.E.Z. designed the research; J.P.N., T.D-O., A.C., J.A.L., F.D.E., and J.M. performed the experiments; J.P.N., T.D-O., and R.E.Z. analyzed the data and wrote the paper. All authors read and approved the final manuscript.

5. Correspondence should be addressed to

Richard E. Zigmond

Case Western Reserve University School of Medicine

Department of Neurosciences

10900 Euclid Avenue

Cleveland OH 44106-4975

E-mail: rez@case.edu

Phone: 216-368-4614

Fax: 216-368-4650

6. Number of Figures: 7 
7. Number of Tables: none

8. Number of Multimedia: none

9. Number of words for Abstract: 249

10. Number of words for Significance Statement: 102

11. Number of words for Introduction: 698

12. Number of words for Discussion: 814

13. Acknowledgements. The authors thank Nisha Malhotra [Case Western Reserve University (CWRU)] and Aubrey Hornak (UCLA) for their technical assistance. We would like to acknowledge use of the Leica SP-8 Confocal Microscope in the Light Microscopy Imaging Facility at CWRU made available through the Office of Research Infrastructure (NIH-ORIP) Shared Instrumentation Grant (S10OD016164). Breeding and genotyping of animals were carried out by the CWRU Visual Sciences Specialized Animal Resources and the Molecular Biology and Genotyping Cores (EY11373). The authors thank Mike Sramkoski of the Cytometry and Imaging Microscopy Core at CWRU for providing guidance with flow cytometry setup and analysis.

Current addresses: T.D-O., Department of Human Genetics, Graduate School of Public Health, University of Pittsburgh, Pittsburgh, PA 15261, J.A.L., Lovelace Biomedical Research Institute, 2425 Ridgecrest Dr SE, Albuquerque, NM 87108, and F.D.E., University of Florida, Department of Neurology, 1329 SW 16th St. Suite 1160, Gainesville, FL 32608.

14. Conflict of interest. 
The authors report no conflicts of interest.

15. Funding. This research was supported by NIH grants NS095017 and DK097223 to R.E.Z., DC00408 and DC013304 to D.D.S., and a 2015-2016 Fulbright Scholar Award to D.D.S. J.P.N. was supported by training grants NS067431 and NS077888 and J.A.L by training grant NS067431 and an NRSA award (F31NS093694). 


\section{Abstract}

Regeneration can occur in peripheral neurons after injury, but the mechanisms involved are not fully delineated. Macrophages in dorsal root ganglia (DRGs) are involved in the enhanced regeneration that occurs after a conditioning lesion $(\mathrm{CL})$, but how macrophages stimulate this response is not known. Oncomodulin $(\mathrm{Ocm})$ has been proposed as a pro-regenerative molecule secreted by macrophages and neutrophils, is expressed in the DRG after axotomy, and stimulates neurite outgrowth by DRG neurons in culture. Wild type (WT) and Ocm knockout (KO) mice were used to investigate whether Ocm plays a role in the $C L$ response in DRG neurons after sciatic nerve transection. Neurite outgrowth was measured after 24 and $48 \mathrm{~h}$ in explant culture $7 \mathrm{~d}$ after a CL. Sciatic nerve regeneration was also measured in vivo $7 \mathrm{~d}$ after a CL and $2 \mathrm{~d}$ after a subsequent sciatic nerve crush. The magnitude of the increased neurite outgrowth following a CL was significantly smaller in explants from Ocm $\mathrm{KO}$ mice than in explants from WT mice. In vivo after a $\mathrm{CL}$, increased regeneration was found in WT animals but not in $\mathrm{KO}$ animals. Macrophage accumulation and levels of interleukin-6 (IL-6) mRNA were measured in axotomized DRG from WT and Ocm KO animals, and both were significantly higher than in ganglia from naïve animals. Our data support the hypothesis that Ocm plays a necessary role in producing a normal CL response and that its effects possibly result in part from stimulation of the expression of pro-regenerative macrophage cytokines such as IL-6. 


\section{Significance Statement}

101 Peripheral neurons are capable of regeneration after axotomy. Regeneration is en-

102 hanced if a conditioning lesion (CL) precedes a test lesion. This CL effect seen in ex-

103 plant cultures does not occur if macrophage accumulation after injury is blocked; however, the mechanism underlying this macrophage effect is not known. To determine whether the macrophage cytokine oncomodulin $(\mathrm{Ocm})$ is involved in this effect, WT and Ocm knockout mice were examined. The CL effect was inhibited in explants from $\mathrm{Ocm}$ knockout animals. Experiments performed in vivo in these two genotypes showed a clear CL effect in the WT mice but none in the Ocm knockout animals. 


\section{Introduction}

Neurons in the peripheral nervous system can regenerate after injury; however, much remains to be clarified about the mechanisms involved. Regeneration is not a neuron autonomous process but instead is influenced by interactions between neurons and both glial cells and immune cells. After axotomy, macrophages play a well-known phagocytic role in the distal nerve segment, clearing discarded myelin and axonal debris (Gaudet et al., 2011; Rotshenker, 2011). In addition, macrophages accumulate around axotomized neuronal cell bodies, which has been shown to play a crucial role in nerve regeneration (Kwon et al., 2013; Niemi et al., 2013) and possibly in neuropathic pain (Yu et al., 2020).

A CL has been shown to enhance outgrowth both in explant culture (Edstrom et al., 1996) and in vivo (McQuarrie and Grafstein, 1973). Subsequent studies have sought to define the neuron-macrophage interaction and identify critical molecules that are involved in the CL response. The chemokine CCL2, and perhaps other macrophage chemokines, bring CCR2+ monocytes from the bloodstream into the axotomized DRG, where they differentiate into macrophages, and promote the CL response (Niemi et al., 2013). What the exact interaction is between the accumulating macrophages and neurons that results in the promotion of regeneration is unclear, although there are many candidate molecules expressed by macrophages that could be involved (Benowitz and Popovich, 2011).

One candidate is $\mathrm{Ocm}$, an EF-hand $\mathrm{Ca}^{2+}$ buffer protein, which was originally detected in rat hepatoma cells (MacManus et al., 1983; Climer et al., 2019). Ocm has since been 
found in outer hair cells of the ear (Sakaguchi et al., 1998; Yang et al., 2004), in macrophages (Yin et al., 2006; Yin et al., 2009), and in neutrophils (Kurimoto et al., 2013). The idea that $\mathrm{Ocm}$ might promote regeneration arose from studies on the regeneration of axons in the optic nerve in response to an inflammatory reaction in the eye. In this context, Ocm was identified as a macrophage-derived growth factor (Yin et al., 2006). When retinal ganglion cells were exposed in culture to Ocm and forskolin, neurite outgrowth was stimulated (Yin et al., 2006). Within a day after initiating inflammation in the eye with zymosan (a yeast cell wall protein-carbohydrate complex), the infiltrating immune cells showed high levels of Ocm mRNA and protein, the latter of which was secreted and bound to retinal ganglion cells. Inflammation-induced stimulation of axon growth following optic nerve crush was significantly reduced by two Ocm-blocking reagents. In addition to macrophages, neutrophils express $\mathrm{Ocm}$, and they are the first responders during inflammation and after injury (Kurimoto et al., 2013; Fine et al., 2020).

However, the importance of Ocm in the context of optic nerve regeneration has been contested. Hauk and colleagues found that Ocm did not increase after lens injury or zymosan treatment and that substantial depletion of macrophages in the eye during inflammation did not prevent regeneration (Hauk et al., 2008). Additionally, they reported that gp130 cytokines such as ciliary neurotrophic factor (CNTF), leukemia inhibitory factor (LIF) and IL-6 secreted by glial cells in the retina are more important in stimulating regeneration than Ocm (Leibinger et al., 2009; Fischer and Leibinger, 2012; Leibinger et al., 2013). Thus, questions have been raised about the importance of Ocm in nerve regeneration.

Three studies examined a role for Ocm in the context of injury to DRG neurons. Yin 
157 duced an increase in neurite outgrowth. Harel et al. (2012) reported what they described

158 as a "meager" effect of Ocm plus dibutyryl cAMP on the growth of DRG neurons across

159 the dorsal root entry zone after a dorsal root nerve crush. Kwon et al. (2013) found an

160 increase in Ocm mRNA in the DRG $7 \mathrm{~d}$ after a sciatic nerve transection and found that a 161 


\section{Materials and Methods}

\section{Animals and surgeries.}

Eight to twelve week old mice with a targeted deletion of exons 2-4 of the Ocm coding sequence were used for this investigation. These Ocm KO mice are designated $\mathrm{Actb}^{\mathrm{cre}} \mathrm{Ocm}^{\text {floxfllox }}$ (Tong et al., 2016). Briefly (as described in Tong et. al., 2016), Ocm KO mice were generated by inserting a LoxP site 5' of exon 2 and Flp-neo-Flp-LoxP cassette was inserted 3' of exon 4 in BAC DNA. The vector was electroporated into ES cells and clones resistant to G418 were isolated and checked for homologous recombination by southern blot analysis. Two male clones were injected into C57BL/6J blastocysts. High percentage chimeras were crossed with CBA/CaJ mice, and the pups were checked for germ-line transmission using southern blots. PCR primers used for genotyping were made from the deleted region (5'-CTC CAC ACT TCA CCA AGC AG-3' and 5'-GCT TGG GGA CCC CCT GTC TTC A-3') and from the targeting vector (5'-CTC CAC ACT TCA CCA AGC AG-3' and 5'-TTT CAT GTT CAG GGA TCA AGT G-3'). The neo gene was removed when generating the Ocm heterozygote to avoid any possible interference. $O \mathrm{~cm}^{\text {flox/flox }}$ mice were generated and crossed with $\beta$-actin Cre mice (strain 003376; The Jackson Laboratory) to generate $\beta$-actin ${ }^{\mathrm{Cre}} \mathrm{Ocm}{ }^{\text {flox/flox }}$ mice (Ocmtm1.1Ddsi, MGI:97401), referred to as Ocm KO mice. For these studies, the Ocm KO mice were backcrossed onto the CBA/CaJ strain (99\% congenicity), and WT and mutant Ocm KO littermates were used. Additional age matched WT mice were acquired from Jackson Laboratory (Bar Harbor, ME, USA; CBA/CaJ) when needed. The animals were housed 3-5 per cage under a $12 \mathrm{~h}: 12 \mathrm{~h}$ light:dark cycle with ad libitum access to food and water. In the mouse, neurons in lumbar DRG L3, L4, and L5 project into the sciatic nerve 
193 (Rigaud et al., 2008). Two lesion protocols were followed. In one, the sciatic nerve was

transected unilaterally under isoflurane anesthesia, and a $2 \mathrm{~mm}$ piece of the distal nerve segment was removed to prevent regeneration. The contralateral nerve was exposed but not transected, and the corresponding ganglia served as sham-operated controls. The animals were sacrificed by $\mathrm{CO}_{2}$ inhalation $7 \mathrm{~d}$ later, and L3 and L4 DRGs and sciatic nerves were removed for neurite outgrowth studies, flow cytometry, and molecular biology. In other experiments, the sciatic nerve was transected unilaterally anterior to its trifurcation, and $7 \mathrm{~d}$ later the nerve was crushed at the level of the sciatic notch. Two days after the second lesion (i.e., the test lesion), the ipsilateral DRG and the sciatic nerve distal to the crush site were analyzed. The contralateral sciatic nerve was exposed and then $7 \mathrm{~d}$ later received a crush lesion. Authors' university's Institutional Animal Care and Use Committee approved all surgical procedures.

\section{DRG explants.}

To assess the outgrowth in response to injury of sensory neurons in culture while maintaining the ganglion's in vivo tissue architecture, neurite outgrowth was evaluated in explanted ganglia from WT and Ocm KO mice after a CL. Seven days after unilateral sciatic nerve transection, axotomized and sham-operated L5 DRGs were removed, desheathed, placed on coverslips, and overlaid with $7.5 \mu$ l Matrigel (Becton Dickinson; Franklin Lakes, NJ, USA). Culture plates were placed in a $37^{\circ} \mathrm{C}$ incubator for 5 min to allow gelling of the Matrigel before adding $1 \mathrm{ml} \mathrm{F12} \mathrm{medium} \mathrm{with} \mathrm{the} \mathrm{following} \mathrm{additives:}$ 0.5\% bovine serum albumin (Jackson ImmunoResearch), 1\% penicillin/streptomycin (Thermo Fisher, Gibco), 5 mg/ml insulin (Millipore Sigma, Burlington, MA, USA), 630 $\mathrm{ng} / \mathrm{ml}$ progesterone (Millipore Sigma), $5 \mathrm{ng} / \mathrm{ml}$ selenium (Millipore Sigma), $9 \mu \mathrm{g} / \mathrm{ml}$ pu- 
trescine (Millipore Sigma), and $100 \mu \mathrm{g} / \mathrm{ml}$ transferrin (BD Biosciences). Phase-contrast images of neurite outgrowth from each DRG were captured at 24 and $48 \mathrm{~h}$ after explantation using an Axiovert $405 \mathrm{M}$ microscope at 10x magnification. Neurite outgrowth was assessed using MetaMorph by measuring the distance between the edge of the ganglion and the leading tip of the longest 20 processes in each explant. The length of these 20 neurites were averaged for each ganglion. Five sham-operated and five axotomized ganglia were analyzed for each genotype. At 48 h, explants were fixed and labeled with an antibody against $\beta$ III tubulin (1:500; Promega; RRID:AB_430874) and the outgrowth was photographed.

\section{In vivo CL studies and regeneration analysis.}

Seven days after a distal unilateral sciatic nerve transection, both sciatic nerves were crushed more proximal to the DRG than the initial nerve transection site. The nerves were crushed for $45 \mathrm{sec}$ with ultra-fine hemostats (Fine Science Tools, Foster City, CA, USA) at the level of the hip. Two days after nerve crush, the animals were sacrificed by $\mathrm{CO}_{2}$ inhalation, and sciatic nerves and L4 DRG were removed for immunohistochemical analysis. Sciatic nerves were removed, cleaned, pinned down straight in a $35 \mathrm{~mm}$ dish, and fixed by immersion in 4\% paraformaldehyde (PFA). Nerves were cryoprotected in 30\% sucrose, embedded in Tissue-Tek O.C.T. (Electron Microscopy Sciences), and sectioned. After blocking, $60 \mu \mathrm{m}$ sections were incubated with an antibody to SCG10 (1:4000; Novus Biologicals; Littleton, CO, USA; RRID:AB_10011569) overnight at $4^{\circ} \mathrm{C}$ and then incubated in AlexaFluor 555 secondary antibodies (1:400; Thermo Fisher Scientific, RRID:AB_162543). Nerves were imaged on a Leica SP8 confocal. The images 
underwent despeckling in ImageJ prior to SCG10 quantification. The regeneration index was measured based on the method of Shin et al. (2014). Briefly, the amount of fluorescence was assessed using MetaMorph in a 100 pixel wide rectangle spanning the width of the nerve where it had been crushed, which was identified by transferring fluorescent microspheres from the tip of the hemostat at the time of the crush (not shown). Another rectangle was placed where the amount of fluorescence was $50 \%$ of that at the crush site. The distance between these two rectangles was measured and expressed as the regeneration index. One section from a crush only animal and one from a conditioned animal, and six to eight animals for each genotype were analyzed. Crush only indicates a nerve harvested $2 \mathrm{~d}$ after a crush injury, and conditioned indicates a nerve harvested $9 \mathrm{~d}$ after a $\mathrm{CL}$ and $2 \mathrm{~d}$ after a crush injury. An additional measure of regeneration was also quantified by measuring the percent area stained by an antibody to SCG10 at 500 $\mu \mathrm{m}$ intervals distal to the crush site and normalizing to the measured percent area stained at the crush site as performed by Weng et al. (2017). These data were represented as a regenerative ratio at each distance.

\section{Macrophage accumulation in vivo.}

The accumulation of macrophages in the sciatic nerve and L5 DRG after an in vivo

CL followed by a nerve crush versus a nerve crush alone was determined. Sciatic nerve sections $(20 \mu \mathrm{m})$ and DRG sections $(10 \mu \mathrm{m})$ from WT and Ocm KO mice were incubated overnight at $4^{\circ} \mathrm{C}$ in an antibody to CD68 (1:200; Bio-Rad; Hercules, CA, USA; RRID:AB_322219) and then incubated in Cy3 secondary antibodies (1:400; Jackson ImmunoResearch; West Grove, PA, USA; RRID:AB_2340619) for $1 \mathrm{~h}$ followed by 4',6diamidino-2-phenylindole (DAPI). Images were captured at 10x (sciatic) or 25x (DRG) 
magnification using HCImage (Hamamatsu Corporation; Bridgewater, NJ, USA) then quantified using MetaMorph. Macrophage cell counts were acquired by counting the number of CD68+ cells containing DAPI using the ImageJ cell counter. For macrophage quantification in the DRG, only areas of tissue containing neuronal cell bodies were analyzed. The total number of cells across three images for each sample was calculated and then averaged for each experimental group. One section from each crush only and each conditioned animal from five (sciatic) or three (DRG) animals for each genotype were analyzed.

\section{Flow cytometry.}

Flow cytometry was performed on pooled L3 and L4 DRG or L3, L4, and L5 DRG after explant culture or after a test lesion in vivo, respectively. Explant and in vivo $\mathrm{CL}$ DRGs were enzymatically digested in $0.125 \%$ collagenase for $1 \mathrm{~h}$ at $37^{\circ} \mathrm{C}$. Mechanical dissociation using a 23-gauge needle attached to a $1 \mathrm{ml}$ syringe produced single-cell suspensions, which were filtered through a $35 \mu \mathrm{m}$ cell strainer. For all cell suspensions, dead cells were labeled using Live Dead Fixable Blue Dead Cell Stain kit (Invitrogen, Cat\#L23105) for 30 min at $4^{\circ} \mathrm{C}$. Cells were then washed in FACS buffer (PBS, 1\% BSA) and blocked with a monoclonal antibody to CD16/CD32 (1:500; eBioscience, RRID:AB_467133) for $10 \mathrm{~min}$ at $4^{\circ} \mathrm{C}$. Cells were incubated with fluorophore-conjugated antibodies against CD11b (1:400, Biolegend, San Diego, CA, USA; RRID:AB_312789) and F4/80 (1:400, Biolegend, RRID:AB_2293450) and Ly6G (1:400, Biolegend, RRID:AB_1134159) for $1 \mathrm{~h}$ at $4^{\circ} \mathrm{C}$. Cells were washed and resuspended on a shaker in fixation buffer (2\% PFA in PBS) for 15 min at room temperature. For flow experiments in which neurons were examined, the cells were then washed in PBS and resuspended in 
permeabilization buffer ( $0.7 \%$ Tween-20 in PBS) on a shaker for 15 min at room temperature. Cells were then incubated with a fluorophore-conjugated antibody against $\beta$ III-tubulin to label neurons (1:80, Biolegend, RRID:AB_2563609) for 30 min at room temperature in the dark. Cells were subsequently washed in FACS buffer and then run on a BD FACSAria (BD Biosciences, San Jose, CA, USA) and analyzed using FlowJo (Tree Star, RRID:SCR_008520). All events were gated based on viable single cells. Compensation and gating were performed using negative, single-stained and isotype controls. Cell populations were gated as follows: $\mathrm{F} 4 / 80^{+} \mathrm{CD} 11 \mathrm{~b}^{+}$(macrophages); $\beta-$ tubulin ${ }^{+} \mathrm{CD} 11 \mathrm{~b}^{-}$(neurons), and $\mathrm{Ly} 6 \mathrm{G}^{+} \mathrm{CD} 11 \mathrm{~b}^{+}$(neutrophils).

\section{Myelin visualization by luxol fast blue.}

To assess myelin clearance in the distal sciatic nerve segment, axotomized and sham-operated sciatic nerves from WT and Ocm KO mice were removed $7 \mathrm{~d}$ after transection and fixed by immersion in 4\% paraformaldehyde. The tissues were cryoprotected in 30\% sucrose and embedded in Tissue-Tek O.C.T. compound. Staining with luxol fast blue (Electron Microscopy Sciences) was performed on $20 \mu \mathrm{m}$ cryostat sections. Briefly, nerves were incubated in $\mathrm{H}_{2} \mathrm{O}, 35 \%$ and $70 \%$ ethanol for 5 min each, followed by incubation in $0.1 \%$ Luxol fast blue overnight at $60^{\circ} \mathrm{C}$. Nerves were subsequently destained in $0.05 \%$ lithium carbonate and incubated for 5 min each in increasing concentrations of ethanol (70\%/95\%/100\%), followed by xylenes before images were captured using a light microscope. Positive myelin staining is expressed as a percentage of the total area examined. Images were captured at 20x magnification using Volocity software (PerkinElmer; Waltham, MA, USA) and then quantified using MetaMorph. Three images per section were analyzed and averaged for each sample. Five samples per genotype 
were analyzed.

\section{Real-time polymerase chain reaction (PCR).}

The expression of three gp130 cytokines (Lif, Cntf, and II-6) was analyzed by quantitative real-time PCR. Six hours and $9 \mathrm{~d}$ after unilateral sciatic nerve transection axotomized and sham-operated L3 and L4 DRG from WT and Ocm KO mice were removed, desheathed, and placed in RNAlater (Thermo Fisher Scientific). Two ganglia were pooled per sample. Three animals were included for each group. The tissue was homogenized, RNA was isolated, total RNA was measured, and $331 \mathrm{ng}$ were reverse transcribed using a High Capacity cDNA Reverse Transcription Kit (Thermo Fisher Scientific). Real-time PCR was performed in an ABI Step-One, using prevalidated TaqMan expression assays (Thermo Fisher Scientific) for Lif (Mm00434762), Cntf (Mm00446373), and II-6 (Mm00446190). Samples were assayed in triplicate and relative expression was determined using the comparative Ct method. mRNA values were normalized to the mRNA values for the internal control glyceraldehyde-3-phosphate dehydrogenase (GAPDH; Mm99999915) of the respective sham group for each genotype.

\section{Statistics.}

Experimenter's performing data analysis were blinded to genotype. Data are expressed as means \pm S.E.M. Statistically significant differences were determine by a twoway ANOVA with a Tukey post-hoc test using GraphPad Prism 9.2.0. Groups are considered statistically different if $p<0.05$. The number of samples per group is indicated in each figure legend. 


\section{Results}

\section{Effects of $\mathrm{Ocm}$ on the $\mathrm{CL}$ response examined in explant culture.}

The increased growth capacity of sensory neurons as the result of a CL can be demonstrated in explant culture and in vivo (McQuarrie and Grafstein, 1973; McQuarrie et al., 1977; Edstrom et al., 1996; Shoemaker et al., 2005). To determine if Ocm is involved in the CL response of DRG neurons, we began by examining the CL response measured in explant culture from WT and Ocm KO mice. Explant cultures enable the in vitro study of neurons while maintaining much of their in vivo tissue environment, including the presence of macrophages as shown in Fig. 1a, e. The number of neurons was also determined for each sample (Fig. 1b, f), and the number of macrophages was also expressed per neuron (Fig. 1c).

After both 24 and $48 \mathrm{~h}$ in culture, DRG explants from both WT and Ocm KO mice exhibited a CL response (Fig. 2a, b): however, the outgrowth from Ocm KO DRG in response to a CL was significantly smaller than that from WT DRG after $48 \mathrm{~h}$ in culture (Fig. 2b-d).

\section{Effects of Ocm on the CL response in vivo.}

We next looked at the CL response in vivo in WT and KO mice. Nine days after a CL (unilateral sciatic nerve transection) and $2 \mathrm{~d}$ after a test lesion (bilateral sciatic nerve crush at a site proximal to the site of transection), sciatic nerves were harvested, sectioned, and labeled with an antibody to SCG10. SCG10 is preferentially expressed in sensory axons, is rapidly down-regulated distal to an injury site, and is highly expressed in regenerating fibers (Shin et al., 2012; Shin et al., 2014). The regeneration index iden- 
tifies the distance from the crush site to the location where levels of SCG10 are half of their levels at the crush site, thus identifying the length to which approximately half of the axons have regenerated (Shin et al., 2014). Under these conditions, we found that sciatic nerves from WT mice exhibited a CL response while those from Ocm KO mice did not (Fig. 3a, c-f).

To examine further the distance the regenerating axons grew in vivo after a $\mathrm{CL}$, a regenerative ratio was also determined by measuring the percent area stained from the site of the crush injury in $0.5 \mathrm{~mm}$ increments distally out to $3 \mathrm{~mm}$ (Fig. 3b). The data were displayed as a ratio of the percent area stained at each individual distance divided by the percent area stained at the crush site. WT conditioned nerves showed significantly more SCG10 staining at $0.5,1,1.5$, and $2 \mathrm{~mm}$ distal to the crush site compared to WT crush only nerves, indicating that a CL increases the length of the axons regenerating in vivo (Fig. 3b). Nerves from Ocm KO mice did not show a significant difference in SCG10 staining in response to a CL at any distance distal to the crush site (Fig. 3b). Additionally, WT conditioned nerves showed significantly more SCG10 staining than Ocm KO conditioned nerves at $2 \mathrm{~mm}$ distal to the crush site (Fig. 3b, d, f). These data indicate that Ocm plays a prominent role in vivo in the CL response of DRG neurons. This in vivo experiment was repeated a second time, and similar results were obtained.

\section{Macrophage accumulation in the absence of $0 \mathrm{~cm}$.}

In an attempt to explore how Ocm might facilitate nerve regeneration in vivo, we examined three factors known to influence regeneration: macrophage accumulation, Wallerian degeneration, and the induction of gp130 cytokines. The accumulation of macro- 
phages in the distal nerve segment of the sciatic nerve after injury has been correlated with nerve regeneration (Bisby and Chen, 1990; Chen and Bisby, 1993; Dailey et al., 1998; Barrette et al., 2008). Therefore, we sought to determine whether Ocm might play a role in the accumulation of macrophages in the sciatic nerve after injury. Using immunohistochemistry, the number of CD68+ macrophages in the nerve was determined either $9 \mathrm{~d}$ after a transection (Conditioned) and $2 \mathrm{~d}$ after a crush injury, or just $2 \mathrm{~d}$ after a crush injury (Crush Only). We found that the CL produced a similar increase in CD68+ cells in the sciatic nerve from both WT and Ocm KO mice (Fig. 4a-e). These data indicate that $\mathrm{Ocm}$ does not influence macrophage accumulation in the distal nerve.

We also assessed the number of CD68+ macrophages in the DRG under the same conditions since macrophage accumulation in the ganglion is correlated with the CL response (Kwon et al., 2013; Niemi et al., 2013). In this tissue, there was a significant increase in CD68+ cells in conditioned DRG from WT mice but not in DRG from conditioned $\mathrm{Ocm} \mathrm{KO}$ mice although this may result in part from the high standard error for this group (Fig. 4f-j).

To obtain a more quantitative measure of macrophage accumulation, CD11b+F4/80+ macrophages were examined in the sciatic nerve and DRG using flow cytometry. The results obtained were similar to those obtained with immunohistochemistry. No difference in macrophage presence in the sciatic nerve was found between genotypes after a CL (Fig.5a, c), but an increase in macrophage accumulation in the DRG was found after a CL in WT but not in Ocm KO mice (Fig. $5 d$, f).

Neutrophils were identified by being positive for CD11b and Ly6G. Such cells are un- 
detectable in the sciatic nerve from sham-operated mice (Lindborg et al., 2017). Following axotomy, no significant differences were found in the sciatic nerve between genotypes or between crush only and a CL followed by crush (Fig. 5b, c). As reported previously (Lindborg et al., 2018), no significant number of neutrophils were found in the DRG from sham-operated or lesioned animals (Fig. 5e, f).

\section{Clearance of myelin in the absence of $0 \mathrm{~cm}$.}

Myelin clearance from the distal nerve after axotomy is important in the peripheral nervous system for subsequent regeneration (e.g., Barrette et al., 2008). Therefore, we examined myelin clearance in WT and Ocm KO mice. The clearance of myelin in the distal sciatic nerve was assessed by staining with luxol fast blue. At $7 \mathrm{~d}$ after sciatic nerve transection, luxol fast blue staining was reduced to the same extent in nerves from WT and Ocm KO mice (Fig. 6). These results indicate that Ocm is not exerting its pro-regenerative effects by influencing myelin clearance.

\section{Effects of Ocm on expression of gp130 cytokines.}

It has been shown that axotomy influences expression of gp130 cytokines in peripheral ganglia (for review see Zigmond, 2012). Although LIF is expressed in the superior cervical ganglion after axotomy, it is not expressed in the axotomized DRG at times examined thus far (Sun and Zigmond, 1996; Thompson et al., 1997). CNTF is expressed in myelinating Schwann cells in the intact sciatic nerve (Dobrea et al., 1992; Rende et al., 1992), but expression actually decreases after nerve transection (Friedman et al., 1992; Sendtner et al., 1992; Seniuk et al., 1992). CNTF was not found in neurons in the DRG in vivo though it is expressed in cultured neurons (Sango et al., 2007). II-6 mRNA 
expression is increased in DRG after axotomy (Murphy et al., 1995). There is a disa-

420 greement in the literature as to whether there is a CL response in DRG neurons from II-

4216 KO mice (Cafferty et al., 2004; Cao et al., 2006). We looked at mRNA expression of

422 these three gp130 cytokines in the DRG $6 \mathrm{~h}$ after a sciatic nerve transection (Fig. 7a)

423 and $7 \mathrm{~d}$ after a conditioning lesion followed by $2 \mathrm{~d}$ after a nerve crush (Fig. 7b). Only II-6

424 expression was affected differentially in WT and Ocm KO animals at the $6 \mathrm{~h}$ time point.

425 Although II-6 increased after axotomy in ganglia from both genotypes, the increase was

426 significantly less in DRG from Ocm KO mice compared to that from WT mice (Fig. 7).

427

428

429 


\section{Discussion}

Our study is the first to look at nerve regeneration in $\mathrm{Ocm} \mathrm{KO}$ mice. Ocm was proposed as a promoter of nerve regeneration based on studies on regeneration of retinal ganglion cell axons following induced ocular inflammation in male Fischer rats (Yin et al., 2006). Benowitz and colleagues reported Ocm protein in the eye and showed that the stimulation of regeneration caused by inflammation could be blocked by reagents that antagonize the action of Ocm (Yin et al., 2009). Fischer and colleagues have presented data supporting a different view of how inflammation leads to the growth of retinal ganglion axons. Working with female Sprague-Dawley rats and female C57BL/6 mice, they reported that the stimulation of regeneration by inflammation is mediated by the release of gp130 cytokines (i.e., CNTF, LIF, and IL-6) from retinal astrocytes (Hauk et al., 2008; Leibinger et al., 2009; Leibinger et al., 2013).

We find that the CL effect measured in sensory neurons in vivo is diminished in Ocm KO mice. In addition, the CL effect measured in explanted DRG was inhibited in KO mice, though it was not completely blocked. Obviously, the in vivo experiment is the most physiologically relevant and makes no assumptions as to the cellular site of action of Ocm. Thus, Ocm might act in the ganglion or in the proximal or distal transected nerve.

It should be noted that in our experiments, we have performed a unilateral conditioning lesion and then compared the effects in the ipsilateral to those in the contralateral DRGs. This comparison may underestimate the magnitude of the effect on the ipsilateral ganglia, as in recent studies in the rat, it has been shown that, after spinal nerve 
transection, some stimulation of gene expression and neurite outgrowth occurs not only in the ipsilateral DRGs but also, though to a lesser extent, in the contralateral DRGs (Hasmatali et al., 2019; Hasmatali et al., 2020; Verge et al., 2020).

Ocm binds to retinal ganglion cells in vivo; however, whether this is also true for cells in the DRG, either neuronal or non-neuronal, is not known. Additionally, an Ocm receptor and an exact signaling pathway in the nervous system have not been defined. The growth effect of Ocm on cultured retinal ganglion cells is completely blocked by the transcriptional inhibitor actinomycin D (Yin et al., 2006). In an earlier study, the CL effect on DRG neurons was similarly shown to be blocked by a different transcriptional inhibitor, 5,6-dichlorobenzimidazole riboside (Smith and Skene, 1997). Our results raise the possibility that $\mathrm{Ocm}$ promotes regeneration of sensory neurons in part by altering neuronal gene expression, specifically the expression of the gp130 cytokine IL-6. IL-6 mRNA has been shown to increase in DRG neurons after axotomy (Murphy et al., 1995). Cafferty et al. (2004) showed that addition of IL-6 to DRG cultures increased neurite outgrowth, and Dubový et al. (2019) showed that intrathecal injection of IL-6 produced a CL-like response after peripheral nerve injury. In the present study, we found that II-6 mRNA was also increased in DRG from Ocm KO mice at $6 \mathrm{~h}$, but to a significantly lesser extent than that from WT animals (Fig. 7). LIF and CNTF, two other members of this cytokine family, were neither induced in the DRG by axotomy nor altered by the absence of Ocm (Fig. 7). Although the time point analyzed here (6 h) is before hematogenous macrophage accumulation in the DRG occurs, it is possible that resident macrophages also express $0 \mathrm{~cm}$. In addition, neutrophils, which can express Ocm, have been shown to accumulate already in the sciatic nerve when examined $8 \mathrm{~h}$ 
after partial nerve injury (Perkins and Tracey, 2000). The possibility that Ocm alters the expression of IL-6 offers a partial resolution of the conflicting views proposed by the Benowitz and Fischer groups described above on whether Ocm or gp130 cytokines mediate the effects of inflammation on optic nerve regeneration.

A finding that was quite unexpected in our study was that accumulation of macrophages in the DRG, though not in the sciatic nerve, was inhibited in the Ocm KO animals (Figs. 4 and 5). This finding raises the possibility that Ocm has chemotactic activity or that it can modulate the expression of monocyte chemokines (e.g., CCL2) or their signaling within the DRG. Under conditions in which macrophage accumulation in the DRG is inhibited, the CL effect is blocked (Niemi et al., 2013).

Often a neuron's ability to initiate axonal growth after an injury is distinguished from its ability to elongate that axon in order to reach its target tissues. Here we observed significantly less outgrowth in vitro from explants of Ocm KO compared to WT mice at $48 \mathrm{~h}$, but not at $24 \mathrm{~h}$, indicating that Ocm may be involved in elongation of regenerating axons rather than initiation of outgrowth.

To promote regeneration and functional recovery, it is likely that a combinatorial approach will be most effective (Benowitz and Popovich, 2011). Prior studies of Ocm have indicated that Ocm can exert its growth-promoting effects in coordination with other agents. For example, it has been shown that increasing retinal levels of $0 \mathrm{~cm}$ and decreasing PTEN expression together can be used to promote regeneration after optic nerve crush (de Lima et al., 2012). In addition, the fact that elevated cAMP levels are required for the pro-regenerative effects of Ocm indicates that there may be other players involved. 
498 In summary, using the Ocm KO mouse, we have demonstrated that this cytokine is 499 necessary for the normal CL response to occur and that this effect could be due to a 500 decrease in the axotomy-induced expression of IL-6 or another macrophage cytokine.

501

502

503

504

505

506 
507 Figure legends

508 Figure 1. Relative macrophage content of DRGs in vivo and in explant culture after a

509

510

CL. For in vivo studies, seven days after a unilateral sciatic nerve transection or contralateral sham surgery, the nerves were crushed bilaterally and nerve regeneration was assayed $2 \mathrm{~d}$ later. For explant studies, DRGs were placed in explant culture for $2 \mathrm{~d}$ after unilateral sciatic nerve transection or contralateral sham surgery. The macrophage (a) and neuronal (b) content of each sample was determined by flow cytometry using two macrophage markers (CD11b and F4/80), one neuronal marker ( $\beta$ III tubulin), and a live/dead cell stain. The ratio of macrophages to neurons is also given (c). Cell counts are also displayed for live cells (d) CD11b+ F4/80+ macrophages (e), and $\beta$-Tubulin+ CD11b- neurons (f). Representative heat maps are shown for CD11b and F4/80 (f) and CD11b and $\beta$ III tubulin $(\mathbf{g})$. Numbers in plots correspond to the percentage of total events in each quadrant. Events in quadrants outlined with a red box correspond to cells that are $\mathrm{CD} 11 \mathrm{~b}^{+} \mathrm{F} 4 / 80^{+}$(f, macrophages) or $\mathrm{CD} 11 \mathrm{~b}^{-} \beta$ III tubulin ${ }^{+}$(g, neurons). $\mathrm{N}=$ 5/group. ${ }^{*} p<0.05,{ }^{* \star} p<0.01,{ }^{* \star *} p<0.001,{ }^{* \star *} p<0.0001$.

Figure 2. L5 DRG explants from both WT and Ocm KO mice exhibited a CL response at $24 \mathrm{~h} \mathrm{(a)}$ and $48 \mathrm{~h} \mathrm{(b),} \mathrm{although} \mathrm{ganglia} \mathrm{from} \mathrm{Ocm} \mathrm{KO} \mathrm{mice} \mathrm{showed} \mathrm{a} \mathrm{significantly}$ smaller response than those from WT ganglia after $48 \mathrm{~h}$ in culture (b). Micrographs represent WT (c) and Ocm KO (d) ganglia following a $\mathrm{CL}$ and $48 \mathrm{~h}$ in culture. $\mathrm{N}=$ 5/group. Scale bars $=250 \mu \mathrm{m} .{ }^{*} p<0.05,{ }^{* *} p<0.01,{ }^{* \star *} p<0.0001$.

Figure 3. DRG from Ocm KO mice do not exhibit a CL response in vivo. Nine days after a CL and $2 \mathrm{~d}$ after a crush injury, axons from WT mice exhibit enhanced growth response in vivo, whereas axons from Ocm KO mice did not (a). The nerves were 
immunostained for SCG10. The regeneration index is the distance from the crush site to the site where the staining for SCG10 is half that seen at the crush site (a, c-f). The regeneration ratio is the ratio of staining at a site to that at the crush site. This ratio was determined for distances from $0.5 \mathrm{~mm}$ to $3.0 \mathrm{~mm}$ distal to the crush site (b). Images represent WT crush only (c) and conditioned plus crush (d) and Ocm KO crush only (e) and conditioned plus crush (f). Asterisks in the images indicate the crush site for each nerve. Dashed rectangles indicate where the immunostaining for SCG10 is reduced by $50 \%$ compared to the staining at the crush site. $N=8$ group. Scale bars $=500 \mu \mathrm{m} . \mathrm{In}$ the line graph, ${ }^{*} p<0.05,{ }^{*} p<0.01$ comparing WT conditioned versus WT crush only. \# p<0.01 comparing WT conditioned versus Ocm KO conditioned.

Figure 4. Macrophage accumulation in the distal sciatic nerve and DRG $2 \mathrm{~d}$ after a nerve crush with and without a prior CL in WT and Ocm KO mice. Macrophage accumulation observed by CD68 immunostaining in the distal sciatic nerve was similar after a CL in both genotypes (a). Macrophage accumulation was also increased in WT DRG after a CL but not in the DRG from Ocm KO mice (f). Three adjacent fields from each sample were counted and summed. Images of WT crush only (b, g) and conditioned plus crush (d, i) and Ocm KO crush only (c, h) and conditioned plus crush (e, j). $N=5$-6/group. Scale bars $=100 \mu \mathrm{m} .{ }^{*} p<0.05,{ }^{* \star} p<0.01,{ }^{* \star *} p<0.001$.

Figure 5. Flow cytometry studies on macrophage and neutrophil accumulation in the distal sciatic nerve and DRG in WT and Ocm KO mice after a nerve crush with and without a prior CL. Macrophages were determined by double staining with antibodies against $\mathrm{CD} 11 \mathrm{~b}$ and F4/80. Neutrophils were determined by double staining with antibodies against CD11b and Ly6G. For animals receiving a CL, the sciatic nerve was 
transected unilaterally $7 \mathrm{~d}$ before the nerve was crushed (samples labeled "CL"). Fortyeight hours later the ipsilateral distal sciatic nerve and the ipsilateral DRG were taken for flow cytometry. The contralateral sciatic nerve received a crush only (samples labeled "Crush"). Representative dot plots for macrophages (a, d) and neutrophils (b, e) in the sciatic nerve $(\mathbf{a}, \mathbf{b})$ and DRG $(\mathbf{d}, \mathbf{e})$. Numbers in plots correspond to the percentage of total events in each quadrant. Events in quadrant outlined with a red box correspond to cells that are $\mathrm{CD} 11 \mathrm{~b}^{+} \mathrm{F} 4 / 80^{+}$(a, $\mathbf{d}$ macrophages) or $\mathrm{CD} 11 \mathrm{~b}^{+} \mathrm{Ly}_{6 \mathrm{G}}{ }^{+}(\mathbf{b}, \mathbf{e}$ neutrophils). Bar graphs indicate mean percent $\mathrm{CD} 11 \mathrm{~b}^{+} \mathrm{F} 4 / 80^{+}$and $\mathrm{CD} 11 \mathrm{~b}^{+} \mathrm{Ly} 6 \mathrm{G}^{+}$ events in the sciatic nerve (c) and DRG (f). $\mathrm{n}=4$ animals per condition per genotype. * $p<0.05,{ }^{* *} p<0.01$.

Figure 6. Myelin clearance from the distal sciatic nerve from WT and Ocm KO mice.

Seven days after unilateral sciatic nerve transection changes in myelin clearance were determined by staining with luxol fast blue. Transected distal nerve segments from WT and Ocm KO mice showed significantly less staining than the sham-operated contralateral nerves, and no difference was seen between genotypes (a). The micrographs represent sections of WT sham-operated nerves (b) and transected distal nerves (d) and sections of Ocm KO sham-operated nerves (c) and transected distal segments (e). $N=5$ /group. Scale bar $=100 \mu \mathrm{m} .{ }^{* \star * \star} p<0.0001$.

Figure 7. II-6 mRNA expression is upregulated in the DRG at various timepoints after sciatic nerve injury. Although an increase was seen in DRG from both WT and Ocm KO mice 6 hours post-sciatic nerve transection, the increase was significantly larger in the former (a). II-6 mRNA expression was not different between WT and Ocm KO mice following a conditioning lesion compared to sham-operated contralateral DRG (b). Lif 
576 and Cntf mRNA was not found to increase with injury in pooled lumbar DRG 6h after a

577 sciatic nerve transection (a) or a conditioning lesion (b). $N=3-5 /$ group. ${ }^{*} p<0.05$, ${ }^{* * *}$

$578 p<0.001,{ }^{* * * *} p<0.0001$.

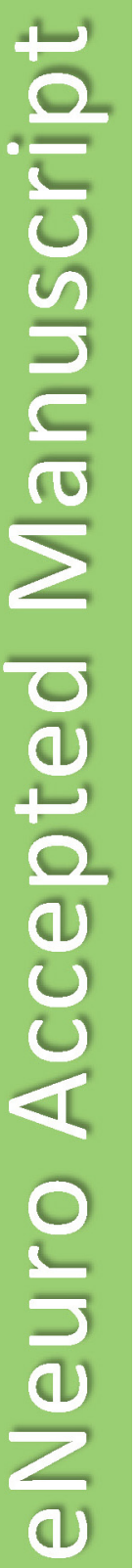




\section{References}

Barrette B, Hebert MA, Filali M, Lafortune K, Vallieres N, Gowing G, Julien JP, Lacroix S (2008) Requirement of myeloid cells for axon regeneration. J Neurosci 28:9363-9376.

Benowitz LI, Popovich PG (2011) Inflammation and axon regeneration. Curr Opin Neurol 24:577-583.

Bisby MA, Chen S (1990) Delayed wallerian degeneration in sciatic nerves of C57BL/Ola mice is associated with impaired regeneration of sensory axons. Brain Res 530:117-120.

Cafferty WB, Gardiner NJ, Das P, Qiu J, McMahon SB, Thompson SW (2004) Conditioning injury-induced spinal axon regeneration fails in interleukin-6 knockout mice. J Neurosci 24:4432-4443.

Cao Z, Gao Y, Bryson JB, Hou J, Chaudhry N, Siddiq M, Martinez J, Spencer T, Carmel J, Hart RB, Filbin MT (2006) The cytokine interleukin-6 is sufficient but not necessary to mimic the peripheral conditioning lesion effect on axonal growth. $\mathrm{J}$ Neurosci 26:5565-5573.

Chen S, Bisby MA (1993) Impaired motor axon regeneration in the C57BL/Ola mouse. J Comp Neurol 333:449-454.

Climer LK, Cox AM, Reynolds TJ, Simmons DD (2019) Oncomodulin: The Enigmatic Parvalbumin Protein. Front Mol Neurosci 12:235.

Dailey AT, Avellino AM, Benthem L, Silver J, Kliot M (1998) Complement depletion reduces macrophage infiltration and activation during Wallerian degeneration and axonal regeneration. J Neurosci 18:6713-6722. 
de Lima S, Habboub G, Benowitz LI (2012) Combinatorial therapy stimulates longdistance regeneration, target reinnervation, and partial recovery of vision after optic nerve injury in mice. Int Rev Neurobiol 106:153-172.

Dobrea GM, Unnerstall JR, Rao MS (1992) The expression of CNTF message and immunoreactivity in the central and peripheral nervous system of the rat. Brain Res Dev Brain Res 66:209-219.

Dubový P, Klusáková I, Hradilová-Svíženská I, Brázda V, Kohoutková M, Joukal M (2019) A conditioning sciatic nerve lesion triggers a pro-regenerative state in primary sensory neurons also of dorsal root ganglia non-associated with the damaged nerve. Front Cell Neurosci 13:11.

Edstrom A, Ekstrom PA, Tonge D (1996) Axonal outgrowth and neuronal apoptosis in cultured adult mouse dorsal root ganglion preparations: effects of neurotrophins, of inhibition of neurotrophin actions and of prior axotomy. Neuroscience 75:11651174.

Fine N, Tasevski N, McCulloch CA, Tenenbaum HC, Glogauer M (2020) The neutrophil: Constant defender and first responder. Front Immunol 11:571085.

Fischer D, Leibinger M (2012) Promoting optic nerve regeneration. Progress in retinal and eye research 31:688-701.

Friedman B, Scherer SS, Rudge JS, Helgren M, Morrisey D, McClain J, Wang DY, Wiegand SJ, Furth ME, Lindsay RM, et al. (1992) Regulation of ciliary neurotrophic factor expression in myelin-related Schwann cells in vivo. Neuron 9:295-305.

Gaudet AD, Popovich PG, Ramer MS (2011) Wallerian degeneration: Gaining 
perspective on inflammatory events after peripheral nerve injury. $\mathrm{J}$ Neuroinflammation 8:110.

Harel R, Iannotti CA, Hoh D, Clark M, Silver J, Steinmetz MP (2012) Oncomodulin affords limited regeneration to injured sensory axons in vitro and in vivo. Exp Neurol 233:708-716.

Hasmatali JCD, De Guzman J, Johnston JM, Noyan H, Juurlink BH, Misra V, Verge VMK (2020) FOXO3a as a sensor of unilateral nerve injury in sensory neurons ipsilateral, contralateral and remote to injury. Neural Regen Res 15:2353-2361.

Hasmatali JCD, De Guzman J, Zhai R, Yang L, McLean NA, Hutchinson C, Johnston JM, Misra V, Verge VMK (2019) Axotomy induces phasic alterations in luman/CREB3 expression and nuclear localization in injured and contralateral uninjured sensory neurons: correlation with intrinsic axon growth capacity. J Neuropathol Exp Neurol 78:348-364.

Hauk TG, Muller A, Lee J, Schwendener R, Fischer D (2008) Neuroprotective and axon growth promoting effects of intraocular inflammation do not depend on oncomodulin or the presence of large numbers of activated macrophages. Exp Neurol 209:469-482.

Kurimoto T, Yin Y, Habboub G, Gilbert HY, Li Y, Nakao S, Hafezi-Moghadam A, Benowitz LI (2013) Neutrophils express oncomodulin and promote optic nerve regeneration. J Neurosci 33:14816-14824.

Kwon MJ, Kim J, Shin H, Jeong SR, Kang YM, Choi JY, Hwang DH, Kim BG (2013) Contribution of macrophages to enhanced regenerative capacity of dorsal root ganglia sensory neurons by conditioning injury. J Neurosci 33:15095-15108. 
Leibinger M, Muller A, Andreadaki A, Hauk TG, Kirsch M, Fischer D (2009) Neuroprotective and axon growth-promoting effects following inflammatory stimulation on mature retinal ganglion cells in mice depend on ciliary neurotrophic factor and leukemia inhibitory factor. J Neurosci 29:14334-14341.

Leibinger M, Muller A, Gobrecht P, Diekmann H, Andreadaki A, Fischer D (2013) Interleukin-6 contributes to CNS axon regeneration upon inflammatory stimulation. Cell Death Dis 4:e609.

Lindborg JA, Mack M, Zigmond RE (2017) Neutrophils are critical for myelin removal in a peripheral nerve injury model of Wallerian degeneration. J Neurosci 37:1025810277.

Lindborg JA, Niemi JP, Howarth MA, Liu KW, Moore CZ, Mahajan D, Zigmond RE (2018) Molecular and cellular identification of the immune response in peripheral ganglia following nerve injury. J Neuroimmunol 15:192-208.

MacManus JP, Watson DC, Yaguchi M (1983) The complete amino acid sequence of oncomodulin--a parvalbumin-like calcium-binding protein from Morris hepatoma 5123tc. Eur J Biochem 136:9-17.

McQuarrie IG, Grafstein B (1973) Axon outgrowth enhanced by a previous nerve injury. Arch Neurol 29:53-55.

McQuarrie IG, Grafstein B, Gershon MD (1977) Axonal regeneration in the rat sciatic nerve: effect of a conditioning lesion and of dbcAMP. Brain Res 132:443-453.

Murphy PG, Grondin J, Altares M, Richardson PM (1995) Induction of interleukin-6 in axotomized sensory neurons. J Neurosci 15:5130-5138.

Niemi JP, DeFrancesco-Lisowitz A, Roldan-Hernandez L, Lindborg JA, Mandell D, 
Zigmond RE (2013) A critical role for macrophages near axotomized neuronal cell bodies in stimulating nerve regeneration. J Neurosci 33:16236-16248.

Perkins NM, Tracey DJ (2000) Hyperalgesia due to nerve injury: role of neutrophils. Neuroscience 101:745-757.

Rende M, Muir D, Ruoslahti E, Hagg T, Varon S, Manthorpe M (1992) Immunolocalization of ciliary neuronotrophic factor in adult rat sciatic nerve. Glia $5: 25-32$

Rigaud M, Gemes G, Barabas ME, Chernoff DI, Abram SE, Stucky CL, Hogan QH (2008) Species and strain differences in rodent sciatic nerve anatomy: implications for studies of neuropathic pain. Pain 136:188-201.

Rotshenker S (2011) Wallerian degeneration: the innate-immune response to traumatic nerve injury. J Neuroinflammation 8:109.

Sakaguchi N, Henzl MT, Thalmann I, Thalmann R, Schulte BA (1998) Oncomodulin is expressed exclusively by outer hair cells in the organ of Corti. J Histochem Cytochem 46:29-40.

Sango K, Yanagisawa H, Takaku S (2007) Expression and histochemical localization of ciliary neurotrophic factor in cultured adult rat dorsal root ganglion neurons. Histochem Cell Biol 128:35-43.

Sendtner M, Stockli KA, Thoenen H (1992) Synthesis and localization of ciliary neurotrophic factor in the sciatic nerve of the adult rat after lesion and during regeneration. J Cell Biol 118:139-148.

Seniuk N, Altares M, Dunn R, Richardson PM (1992) Decreased synthesis of ciliary neurotrophic factor in degenerating peripheral nerves. Brain Res 572:300-302. 
Shin JE, Geisler S, DiAntonio A (2014) Dynamic regulation of SCG10 in regenerating axons after injury. Exp Neurol 252:1-11.

Shin JE, Miller BR, Babetto E, Cho Y, Sasaki Y, Qayum S, Russler EV, Cavalli V, Milbrandt J, DiAntonio A (2012) SCG10 is a JNK target in the axonal degeneration pathway. Proc Natl Acad Sci U S A 109:E3696-3705.

Shoemaker SE, Sachs HH, Vaccariello SA, Zigmond RE (2005) A conditioning lesion enhances sympathetic neurite outgrowth. Exp Neurol 194:432-443.

Smith DS, Skene JH (1997) A transcription-dependent switch controls competence of adult neurons for distinct modes of axon growth. J Neurosci 17:646-658.

Sun Y, Zigmond RE (1996) Leukaemia inhibitory factor induced in the sciatic nerve after axotomy is involved in the induction of galanin in sensory neurons. Eur $\mathrm{J}$ Neurosci 8:2213-2220.

Thompson SW, Vernallis AB, Heath JK, Priestley JV (1997) Leukaemia inhibitory factor is retrogradely transported by a distinct population of adult rat sensory neurons: co-localization with trkA and other neurochemical markers. Eur J Neurosci 9:1244-1251.

Tong B, Hornak AJ, Maison SF, Ohlemiller KK, Liberman MC, Simmons DD (2016) Oncomodulin, an EF-Hand Ca2+ buffer, is critical for maintaining cochlear function in mice. J Neurosci 36:1631-1635.

Verge VMK, Hasmatali JCD, Misra V (2020) When the left side knows something happened to the right - sensing injury in neurons contralateral and remote to injury. Neural Regen Res 15:1854-1855.

Weng YL, An R, Cassin J, Joseph J, Mi R, Wang C, Zhong C, Jin SG, Pfeifer GP, 
Bellacosa A, Dong X, Hoke A, He Z, Song H, Ming GL (2017) An intrinsic epigenetic barrier for functional axon regeneration. Neuron 94:337-346 e336.

Yang D, Thalmann I, Thalmann R, Simmons D (2004) Expression of $\alpha$ and $\beta$ parvalbumin is differentially regulated in the rat organ of corti during development. Journal of neurobiology 58:479-492.

Yin Y, Henzl MT, Lorber B, Nakazawa T, Thomas TT, Jiang F, Langer R, Benowitz LI (2006) Oncomodulin is a macrophage-derived signal for axon regeneration in retinal ganglion cells. Nat Neurosci 9:843-852.

Yin Y, Cui Q, Gilbert HY, Yang Y, Yang Z, Berlinicke C, Li Z, Zaverucha-do-Valle C, He H, Petkova V, Zack DJ, Benowitz LI (2009) Oncomodulin links inflammation to optic nerve regeneration. Proc Natl Acad Sci U S A 106:19587-19592.

Yu X, Liu H, Hamel KA, Morvan MG, Yu S, Leff J, Guan Z, Braz JM, Basbaum Al (2020) Dorsal root ganglion macrophages contribute to both the initiation and persistence of neuropathic pain. Nat Commun 11:264.

Zigmond RE (2012) gp130 cytokines are positive signals triggering changes in gene expression and axon outgrowth in peripheral neurons following injury. Front Mol Neurosci 4:1-18. 


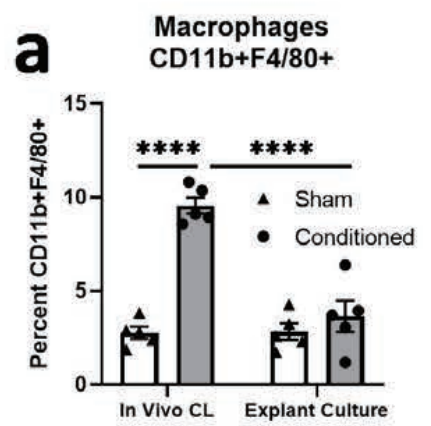

b $\beta$-Tubulin+CD11b-

C Macrophages:Neurons
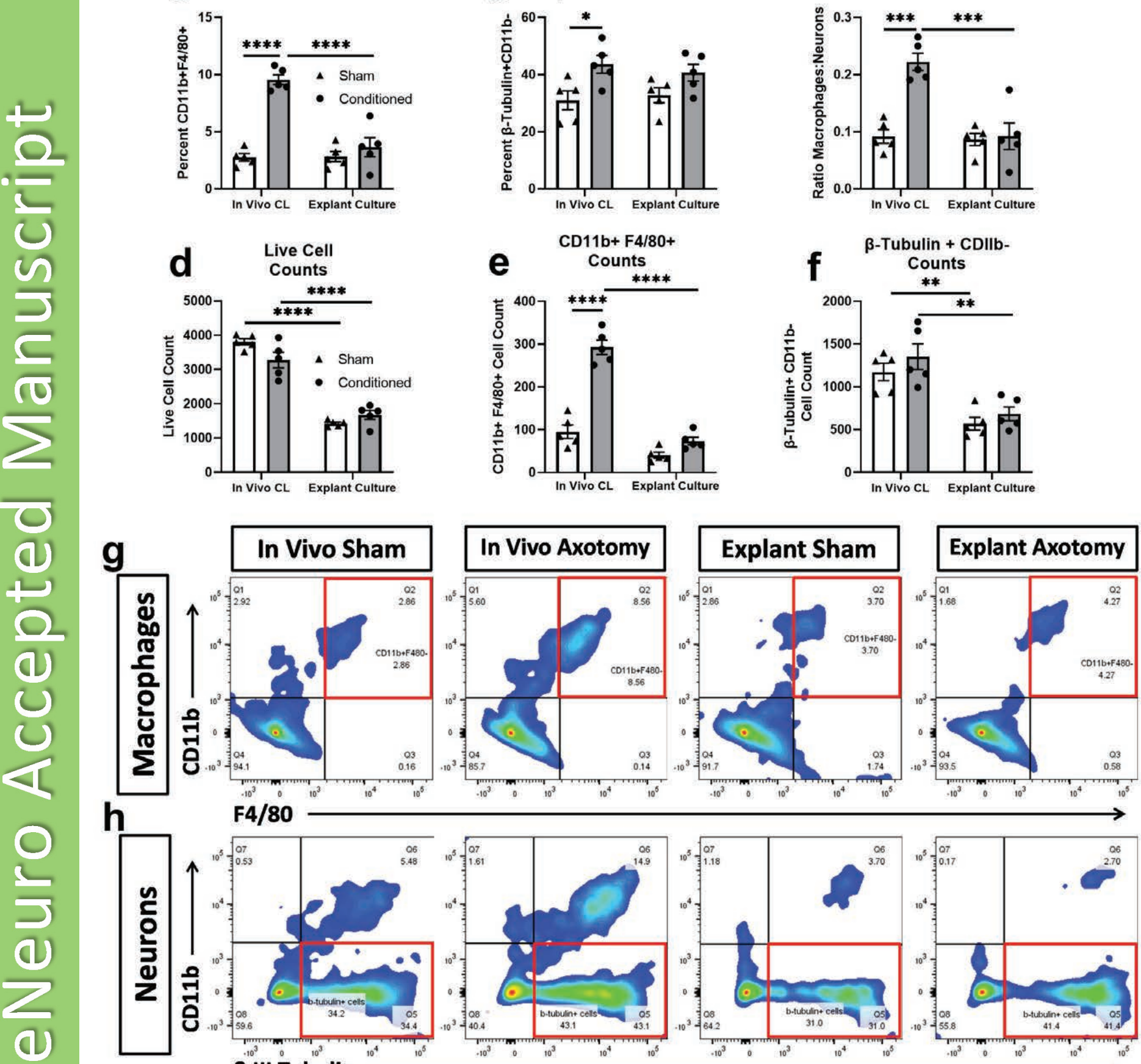

h

$F 4 / 80$
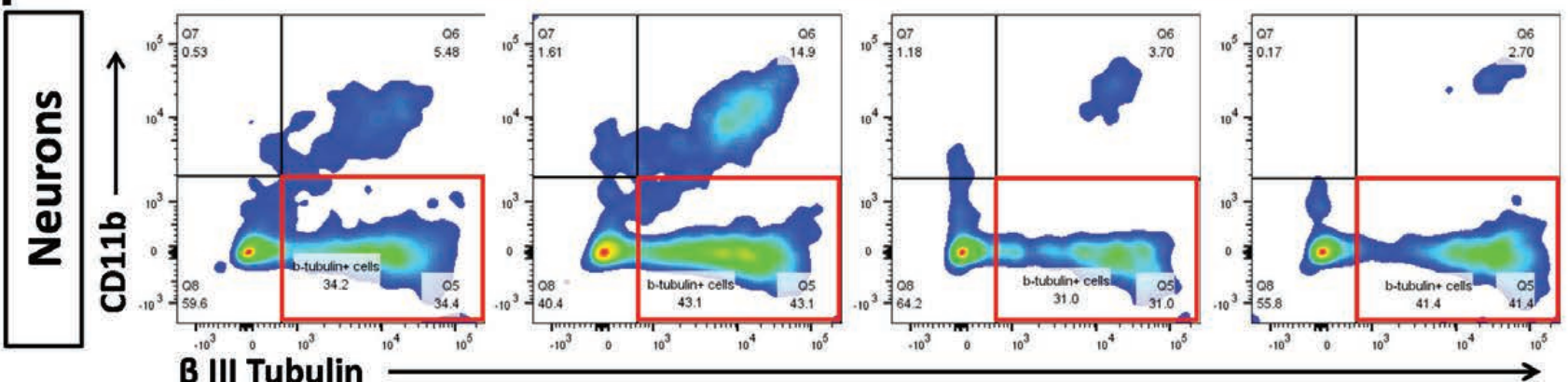

B III Tubulin 
a
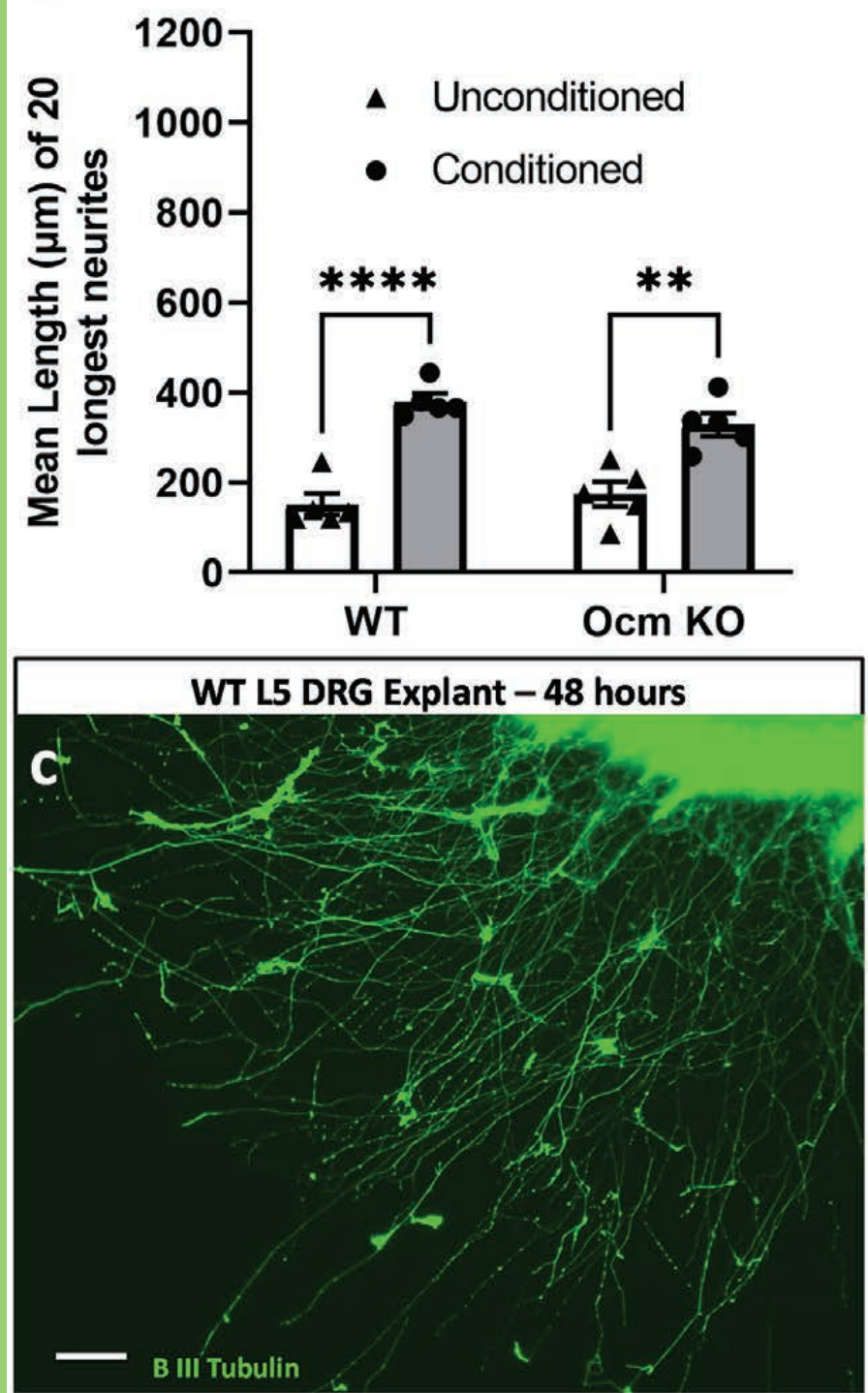

b
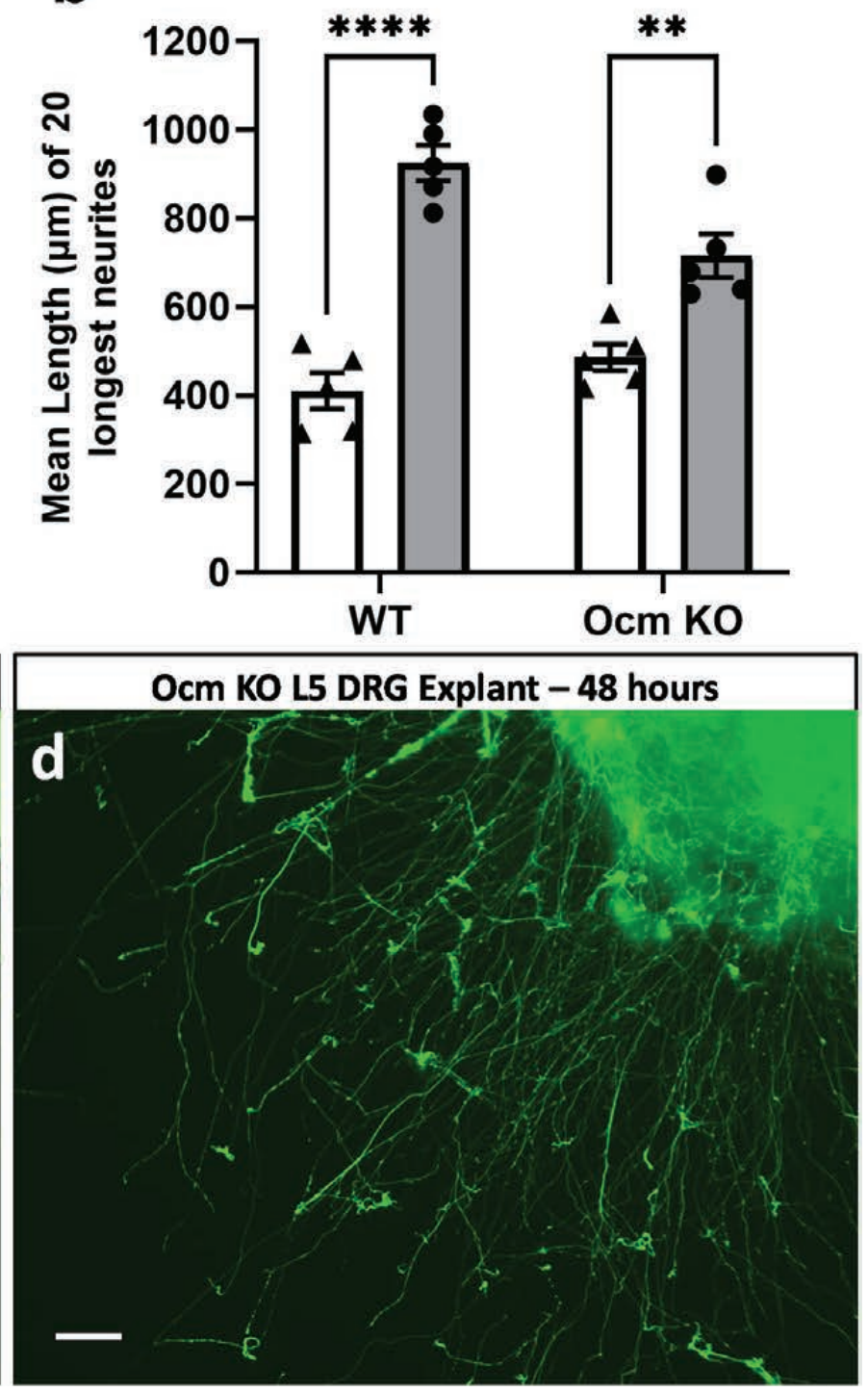

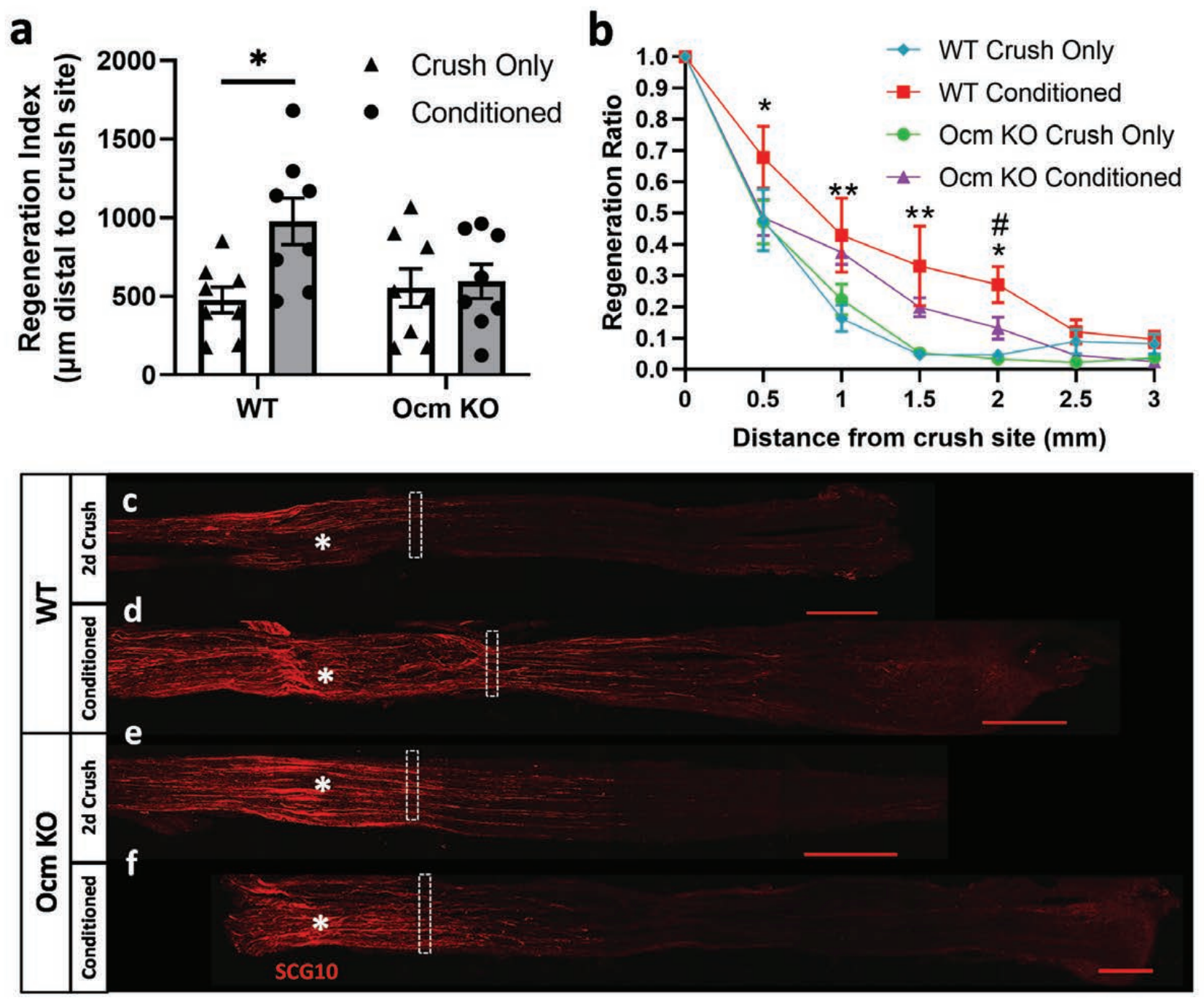
a
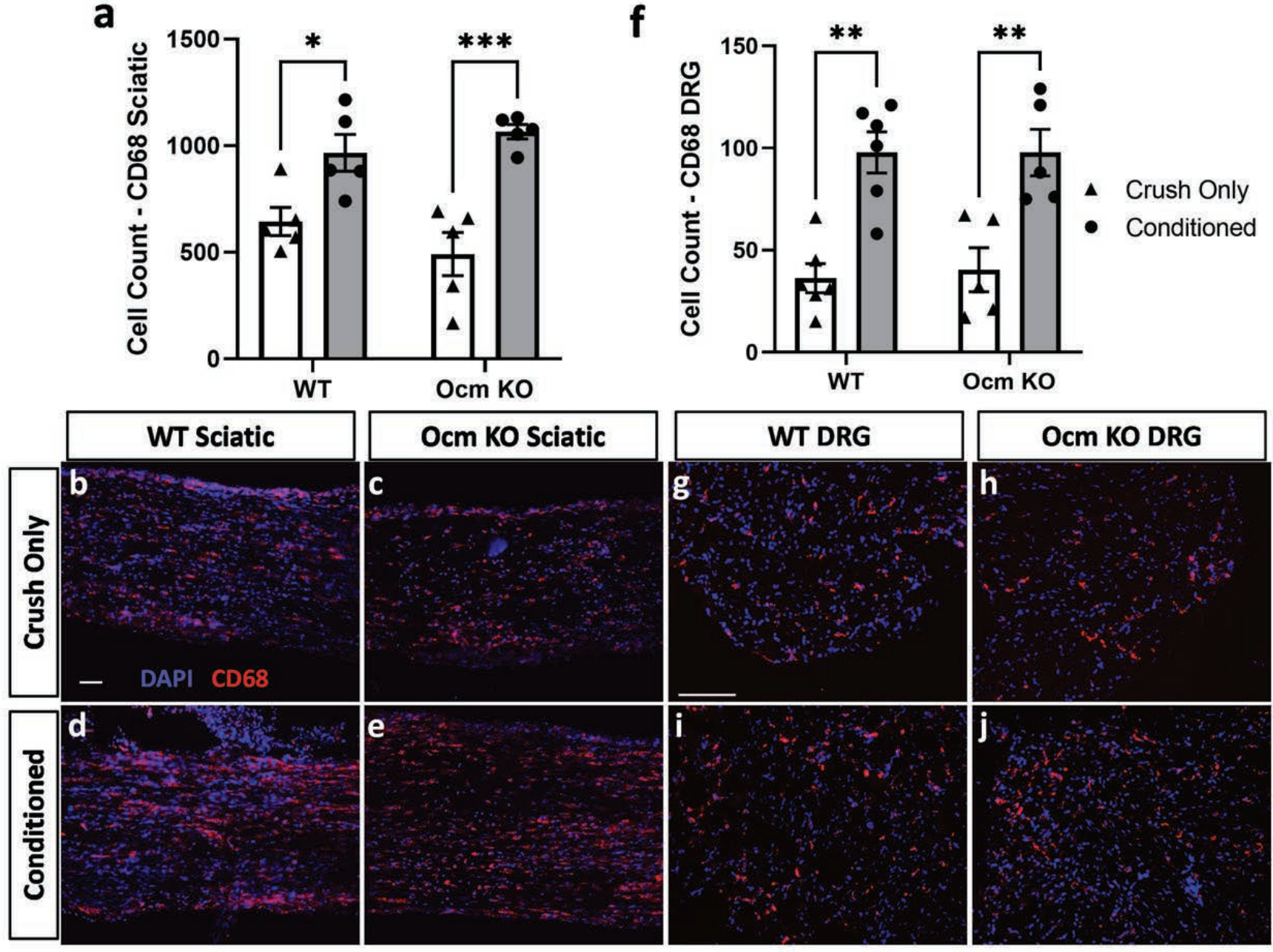

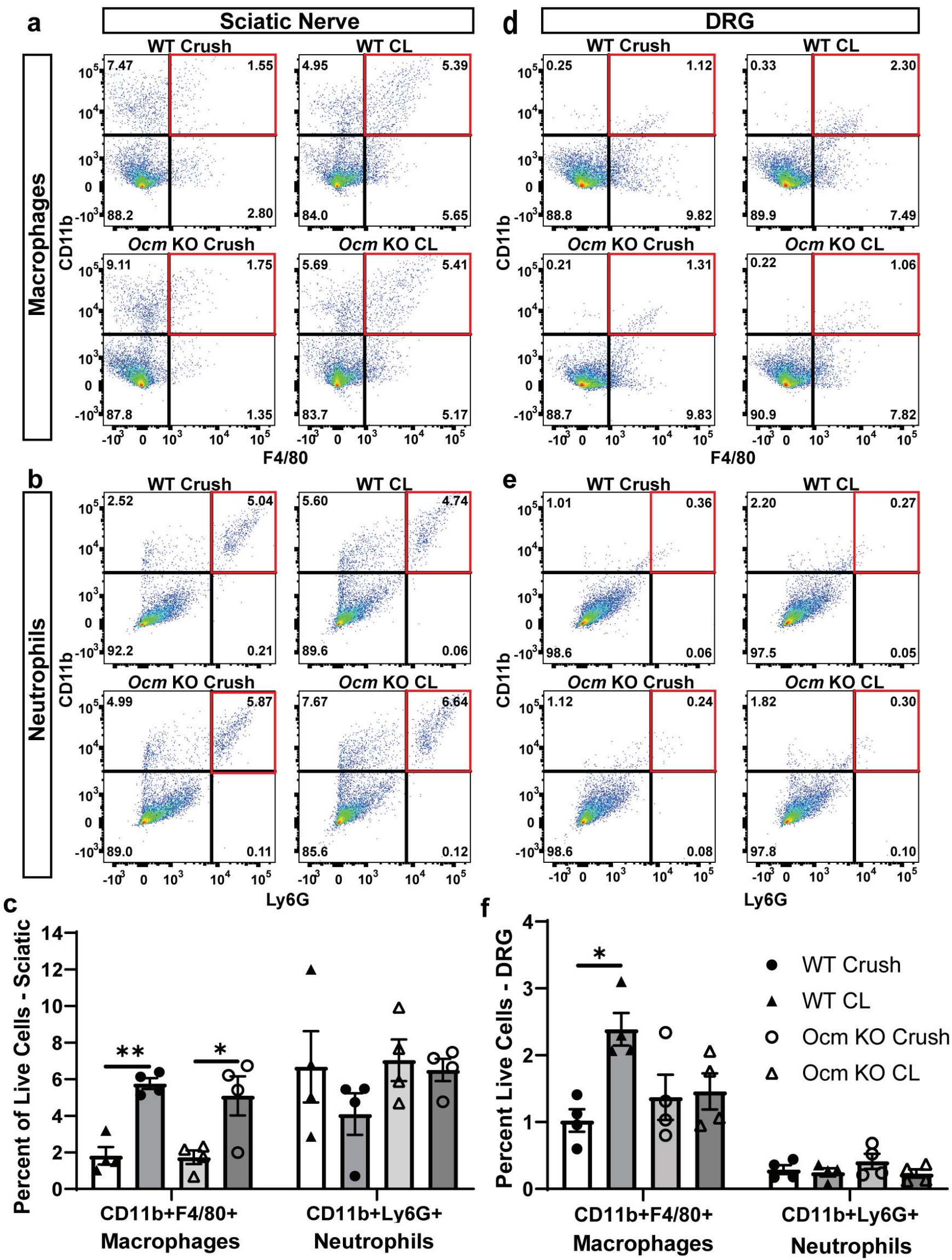

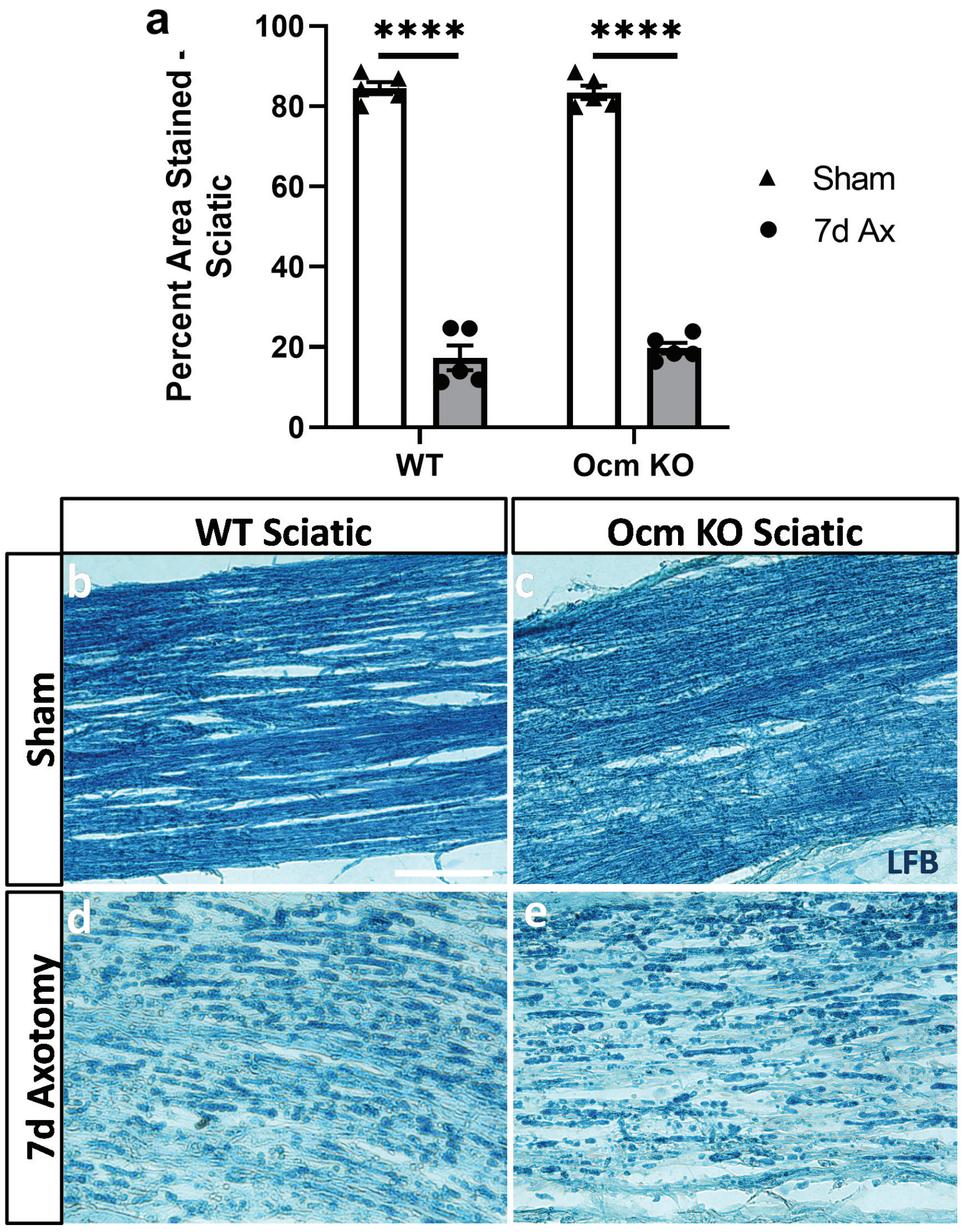
a

宅

$$
\text { 은 }
$$

응

(1)

흠

离

$\sum_{\substack{\frac{\pi}{d}\\}}^{0}$

b

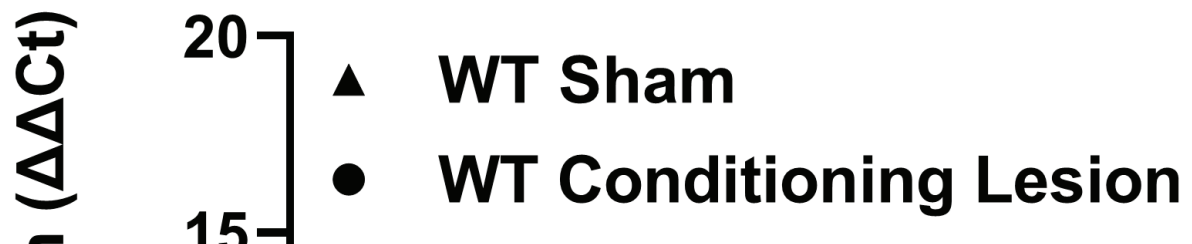

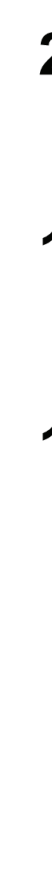

20
15
10

- WT Sham

- WT 6h Axotomy

$* * * *$

****

$\Delta$ Ocm KO Sham

- Ocm KO 6h Axotomy

$* * * *$

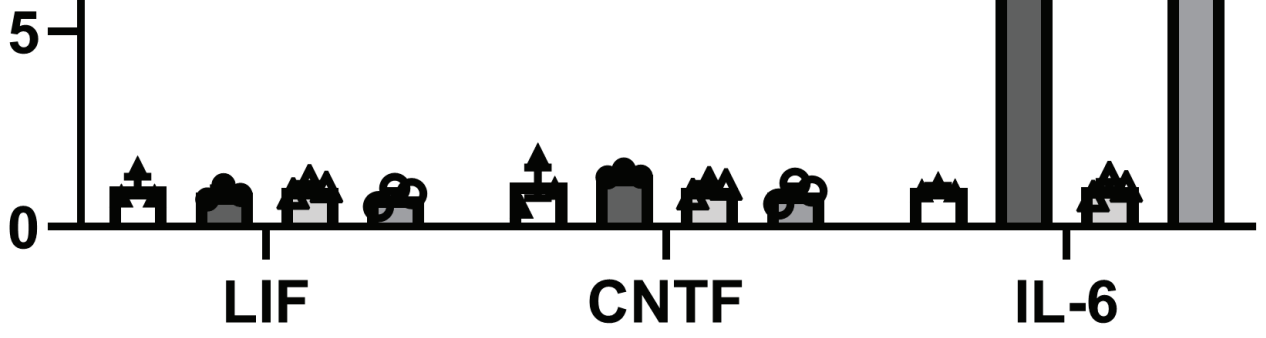

읍 $15-\Delta$ Ocm KO Sham

\& ${ }_{10}$ o Ocm KO

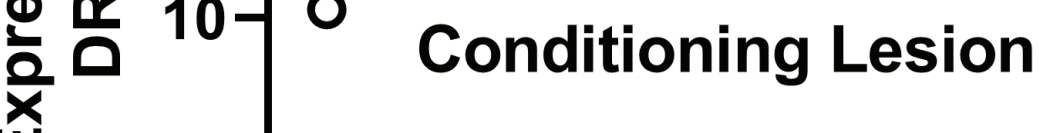

ய

$\frac{\$}{\frac{0}{0}}$

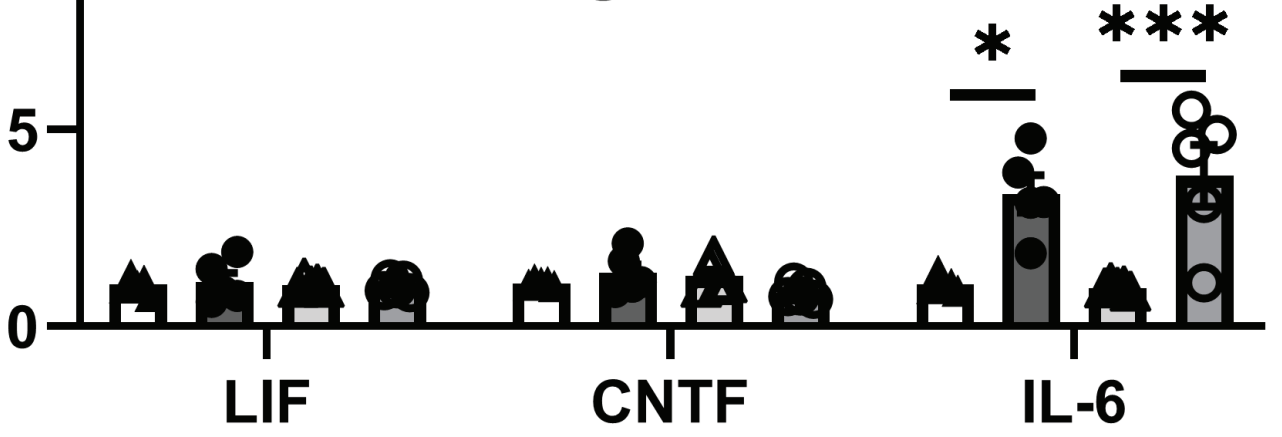

